Proceedings of the 24th International Symposium "The Environment and the Industry" (E-SIMI 2021), 24 September 2021, online event

\title{
Moving forward sustainable solutions for VOCs biotrickling filtration through co-immobilised microorganisms
}

\section{GABRIELA SOREANU*, MARIANA DIACONU, STELIAN SERGIU MAIER, IRINA VOLF, IGOR CRETESCU*}

“Gheorghe Asachi” Technical University of Iasi, 73 D. Mangeron Blvd, Iasi 700050, Romania

*Corresponding authors: gsor@tuiasi.ro; icre@tuiasi.ro

$\begin{array}{lll}\text { Received: } & \text { Accepted: } & \text { Published: } \\ \text { 01.09.2021 } & 03.11 .2021 & 17.12 .2021\end{array}$

\section{Abstract}

This study is moving forward some available options for upgrading the biotrickling filters (BTFs) treating volatile organic compounds (VOCs) in air, in the light of lowering their greenhouse gas $(G H G)$ emissions. One of such options refers to the addition of the microalgae component to the biological matrix involved in such systems, by (co)immobilization, for the capture of the carbon dioxide issued from the VOCs biodegradation and potentially contributing to the overall VOCs removal performance. Particularly, alginate beads with (co)immobilised microorganisms (microorganisms isolated from commercial compost and microalgae Arthrospira platensis PCC 8005) are for the first time tested for this purpose, as following: beads with entrapped compostbased microorganisms and attached microalgae (BTF-I); beads with entrapped mixture of microalgae and compost-based microorganisms (BTF-II). Although the both options provided promising performances in treating air contaminated with ethanol (as a model VOC in this study), the last option exhibited lower $\mathrm{CO}_{2}$ emissions and higher packing bed durability, being more prone to further development and implementation.

Keywords: alginate beads, Arthrospira platensis, co-immobilisation, compost, biotrickling filtration

\section{INTRODUCTION}

Microbiological removal of volatile organic compounds (VOCs) from contaminated air streams is based on their conversion by aerobic heterotrophic microorganisms into less harmful compounds, such as carbon dioxide. High performances in VOCs removal are reported for various biosystems used for this purpose (e.g. biofilters, biotrickling filters) [1,2]. Particularly, carbon dioxide production of such systems is usually evaluated as an indicator of the biological activity. On the other hands, the carbon dioxide is a greenhouse gas (GHG) and its production can reduce the overall environmental performance of the biosystems treating VOCs in air, by contributing to the increase of their global warming potential (GWP). This last aspect is rather neglected in the available studies related to the biological VOC removal, despite the needs for developing lower $\mathrm{CO}_{2}$ emissions systems, taking into consideration the actual climate change issues. Thus, the raised challenge is to develop high performance VOCs removal biosystems with lower $\mathrm{CO}_{2}$ emissions. One option in this regard is to co-immobilise heterotrophic microorganisms (able to degrade VOCs) and microalgae (able to uptake $\mathrm{CO}_{2}$ issued from VOCs degradation) to simultaneously achieve VOCs and $\mathrm{CO}_{2}$ removal in the same unit [3]. There are several possibilities for the immobilisation of the microorganisms, such as those based on 
adsorption, attachment, encapsulation/entrapment etc. [4, 5]. Particularly, the microorganisms can be immobilised in beads of natural or synthetic polymeric materials, this option allowing an easier separation than the suspended-cells based systems and a better control of the involved species $[6,7]$.

So far, different microalgae species have been investigated in the frame of wastewater treatment, which could have perspectives in air treatment (including organic compounds removal) where this type of application is less represented. Among the species, it could be mentioned [8-10]: Chlorella sp., Picochlorum sp., Scenedesmus obliquus, Micratinium reisseri etc. Moreover, coupling microalgae-bacteria exhibited promising results in the treatment of different types of wastewaters by using different photobioreactor configurations. For example, a biotrickling filtertype containing an algal-bacterial consortium was used by Katam et al. [11] for the removal of linear alkylbenzene sulphonate and caffeine from synthetic wastewater, while piggery wastewater was treated in an open photobioreactor containing an algal-bacterial consortium [10, 12].

In the previous study [3], a mixture of microalgae (A. platensis PCC 8005) and compost-based microorganisms, attached on an inert support, was successfully used for the ethanol removal from air by biotrickling filtration, demonstrating the proposed concept. In the actual study, alginate beads with (co)immobilised microorganisms are for the first time tested for this purpose, as well. Contribution of this option to the biotrickling filters environmental performance (not only VOCs removal, but also $\mathrm{CO}_{2}$ removal) is presented and discussed.

\section{EXPERIMENTAL PART}

Biological cultures

The following cultures were used as a source of microalgae and compost-based microorganisms, respectively:

- a submerged culture of Arthrospira platensis PCC 8005 (Pasteur Culture Collection, France) of about $0.4 \mathrm{~g} / \mathrm{L}$ biomass, developed in a Zarrouk medium;

- a culture of microorganisms isolated from the commercial compost (peat-based, with active humus), obtained as following described.

Isolation of the microbial consortium from compost was achieved by serial dilutions (e.g. $1 \mathrm{~g}$ of compost, suspended in $100 \mathrm{~mL}$ of sterile physiological saline solution and homogenized at $150 \mathrm{rpm}$ for $60 \mathrm{~min}$, was subject to successive dilutions, e.g. up to $10^{-6}$ dilution degree; the last dilutions were seeded $\left(1 \mathrm{ml}\right.$ each) on agar media distributed in Petri dishes, which were incubated at $28 \pm 1^{\circ} \mathrm{C}$ for 48 hours, allowing the development of a dense and diversified microbiota. The content of a plate (dilution $10^{-5}$ ) was passed on a liquid culture medium (in fermentation - $200 \mathrm{~mL}$ medium) to obtain the inoculum of the microbial consortium. After 24 hours of development under aeration and stirring (180 rpm) at $28^{\circ} \mathrm{C}$, the inoculum was transferred to 2 liters of culture medium and cultured submerged for 72 hours at $180 \mathrm{rpm}$ and $28{ }^{\circ} \mathrm{C}$ to obtain the necessary biomass for the immobilization process. A culture of about $2 \mathrm{~g} / \mathrm{L}$ biomass was obtained in this way.

\section{Immobilisation of the microorganisms}

The biomass obtained from the above mentioned cultures was used for the (co)immobilisation of the microorganisms into the alginate beads; in this regard, the target biomass was mixed with sterile $4 \%$ alginate solution, stirred for $15 \mathrm{~min}$ and then dripped into $2 \% \mathrm{CaCl}_{2}$ solution under periodic mixing, to form the alginate beads with entrapped microorganisms; the obtained beads (4-5 mm diameter) were left for $1 \mathrm{~h}$ in the solution and then washed with a sterile saline solution (Fig. 1).

Two types of alginate beads were obtained:

- type I: alginate beads with entrapped compost-based microorganisms and attached microalgae (in this case, the beads were temporary immersed in a dense culture of A. platensis in order to allow the microalgae attachment on their surface) 
- type II: alginate beads with entrapped mixture of compost-based microorganisms and microalgae (a ratio of 0.33 microalgae: compost-based microorganisms was considered for the preparation of the beads in this case).

In the above mentioned description of the alginate beads, the term "entrapped" and "attached" were used in order to distinguish between these different immobilisation options. Thus, alginate beads of type I contained microorganisms isolated from compost fixed within the internal bead structure (entrapped) and microalgae fixed on the bead surface (attached), while the alginate beads of type II contained both compost-based microorganisms and microalgae entrapped inside the bead structure.

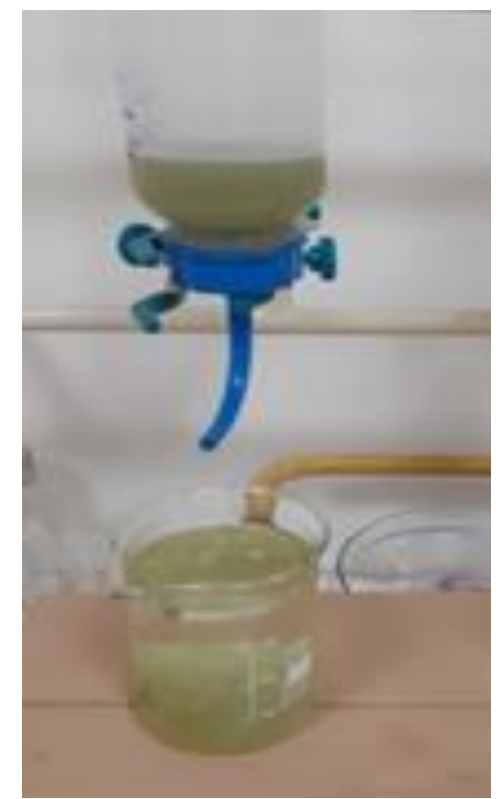

a)

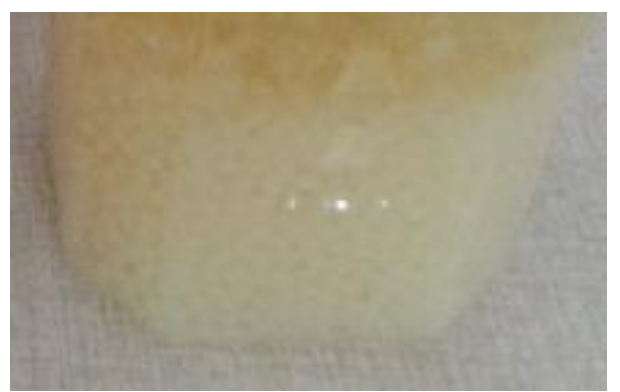

b)

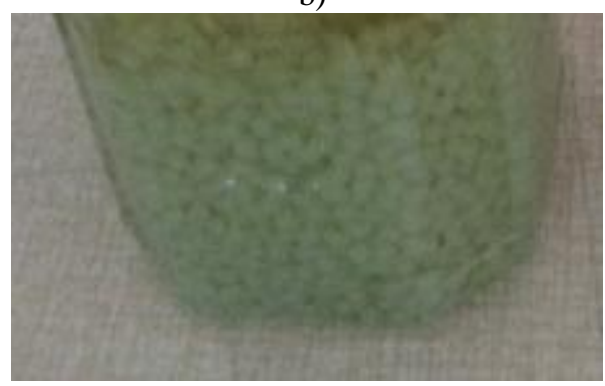

c)

Fig.1. Images of alginate beads preparation: a) principe of the microorganisms-rich alginate beads formation; b) alginate beads containing immobilised compost-based microorganisms; c) alginate beads containing co-immobilised microalgae and compost-based microorganisms.

Various particular aspects related to the immobilization of the microalgae biomass using alginate are available elsewhere [6, 13-15].

\section{Experimental set-up and methodology}

Experiments have been carried out in transparent PVC-made biotrickling filters (BTFs) of $10 \mathrm{~cm}$ column diameter, which were packed up to $11 \mathrm{~cm}$ height with alginate beads of type I (for the BTFI) or type II (for the BTF-II), earlier described. Each BTF was continuously illuminated by two white LED arrays, oppositely located, to allow the photosynthesis, at a constant light intensity of 30 Klux each side, measured with a digital lux meter (Extech, Light Meter LT300). An aluminium folium was placed around for a better light control.

BTFs were operated as described in our previous study [3], where a diagram of the experimental installation is also available. BTFs were continuously fed with synthetically contaminated air (using ethanol as model pollutant/VOC) and recycled nutrient solution $(2.5 \mathrm{~L}$, Zarouk-medium based, free of sodium bicarbonate/sodium chloride, initial $\mathrm{pH}$ adjusted at 9.5 with sodium hydroxide), in counter-current, for about three weeks. The $\mathrm{pH}$ and nutrients were occasionally adjusted, upon request.

Several parameters have been regularly monitored, such as carbon dioxide and ethanol concentration for the gaseous flux and $\mathrm{pH}$, nitrate and dissolved oxygen for the liquid flux. A Micro-GC Fusion Gas Analyzer (Inficon, USA), equipped with thermal conductivity detector, was used for the gas analysis, while HACH devices (HACH multi-parameter, HACH DR/2010 spectrophotometer) and reagents kits were used for the liquid analysis. 
Pollutant loading rate (LR, mass / (packing bed volume - time)) was varied by varying the inlet ethanol concentration (between $60-580 \mathrm{ppm}$ ) or the gas flowrate (between $0.75-2 \mathrm{~L} / \mathrm{min}$ ) and the corresponding elimination capacity (EC, mass / (packing bed volume $\cdot$ time)) was determined, along with the carbon dioxide production rate ( $\mathrm{P}_{\mathrm{CO} 2}$, mass / (packing bed volume $\cdot$ time)) and the pollutant removal efficiency (RE, \%). Inlet $\mathrm{CO}_{2}$ concentration in the processed air ranged between 300-350 ppm. Few samplings per day were performed for gas analysis.

The above-mentioned performance criteria (LR, EC, $\mathrm{P}_{\mathrm{CO} 2}, \mathrm{RE}$ ) are calculated as described elsewhere [16].

\section{RESULTS AND DISCUSSION}

\section{$\mathrm{CO}_{2}$ production}

Figure 2 shows the variation of the carbon dioxide production rate $\left(\mathrm{P}_{\mathrm{CO} 2}\right)$ as a function of the ethanol elimination capacity (EC) for the two investigated BTFs (BTF-I, BTF-II). The selected data correspond to the maximum ethanol removal efficiency $(\mathrm{RE}=100 \%)$. As can be seen, $\mathrm{P}_{\mathrm{CO} 2}$ increases with EC increase, however more carbon dioxide is produced during the BTF-I operation than observed for BTF-II, especially at EC values above $20 \mathrm{~g} /\left(\mathrm{m}^{3} \cdot \mathrm{h}\right)$. This might suggest that mass transfer involved in $\mathrm{CO}_{2}$ uptake was enhanced in the case of alginate beads of type II (beads with entrapped mixture of compost-based microorganisms and microalgae) as compared with those of type I (beads with entrapped compost-based microorganisms and attached microalgae). The amount of the microalgae attached on the alginate beads of type I may be less than that entrapped in the case of type II, which could make a difference in terms of $\mathrm{P}_{\mathrm{CO} 2}$.

On the other hands, it should be noted that the slope related to BTF-I (0.916) is still below the slope of the reference linear curve related to the oxidation of the ethanol without any biomass production and close to the best performing BTF (1.017) in the previous study [3], which involved coimmobilisation of microalgae and compost based-indigenous microorganisms by their attachment on an inert support.

The lower $\mathrm{P}_{\mathrm{CO} 2}$ in the actual study could be attributed to the absence of protozoa $\left(\mathrm{CO}_{2}\right.$-producers, [3]), as deducted from microscopy investigation (results not shown), due the particular microbiological conditions associated with the use of the isolated microorganisms from compost and, moreover, their entrapment along with the microalgae in the alginate beads, which allowed a better species control in the system.

Overall, BTF-II exhibits the smallest $\mathrm{P}_{\mathrm{CO} 2}$ among all tested configurations in the actual and the previous study. Monitoring of chlorophyll a concentration from the biomass could be further considered for the evaluation of the microalgae biomass concentration and photosynthetic activity in such systems.

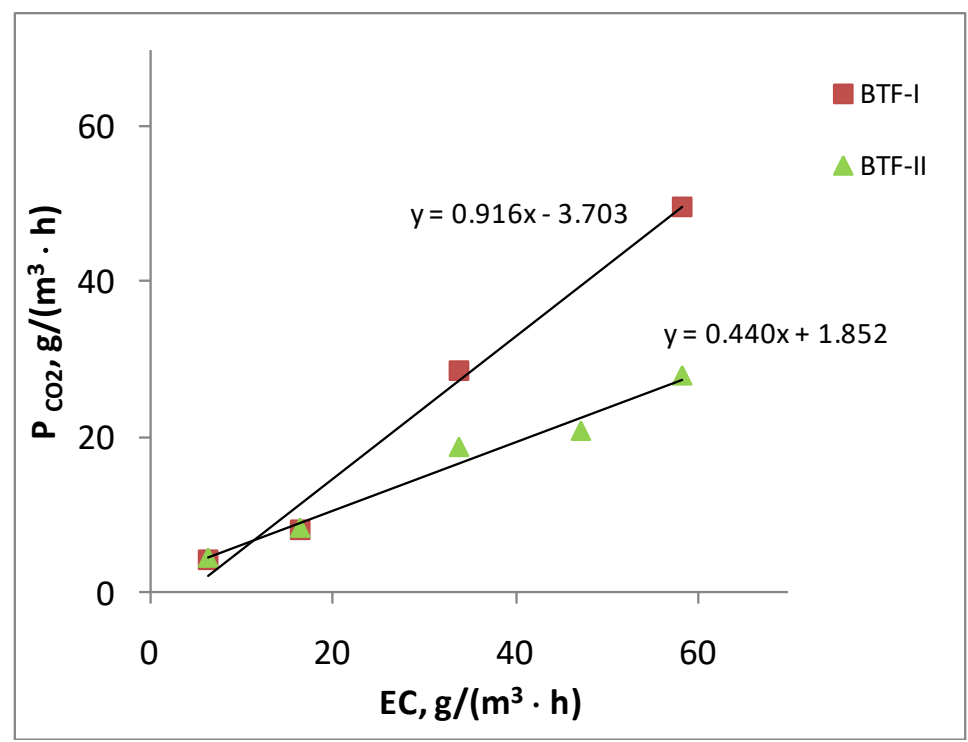

Fig. 2. Variation of the carbon dioxide production rate $\left(\mathrm{P}_{\mathrm{CO} 2}\right)$ with the ethanol elimination capacity (EC), for BTF-I and BTF-II 


\section{VOCs removal}

It should be noted that at higher ethanol loading rates, the alginate beads of BTF-I began to physically colaps, in contrast to BTF-II where the alginate beads were more stable. The colaps could be associated with the excesive accumulation of metabolites in the nutrient solution, and/or with a low exchange rate of $\mathrm{CO}_{2}$ produced by the entrapped VOCs-degraders inside of alginate beads towards the microalgae attached on the bead surface. Therefore, the best working option in this study is to use BTF-II beads, mainly because of the longer-term stability of the polymeric beads under various operating conditions. This is why, in the further experiments as presented below, the variation of the ethanol elimination capacity (EC) as a function of the ethanol loading rate (LR) was determined working with BTF-II. According to Fig. 3, EC linearly increases with LR up to 1400 $\mathrm{g} /\left(\mathrm{m}^{3} \cdot \mathrm{d}\right)$, after which a slight change in the curvature occurs due the RE decrease at higher loading rates.

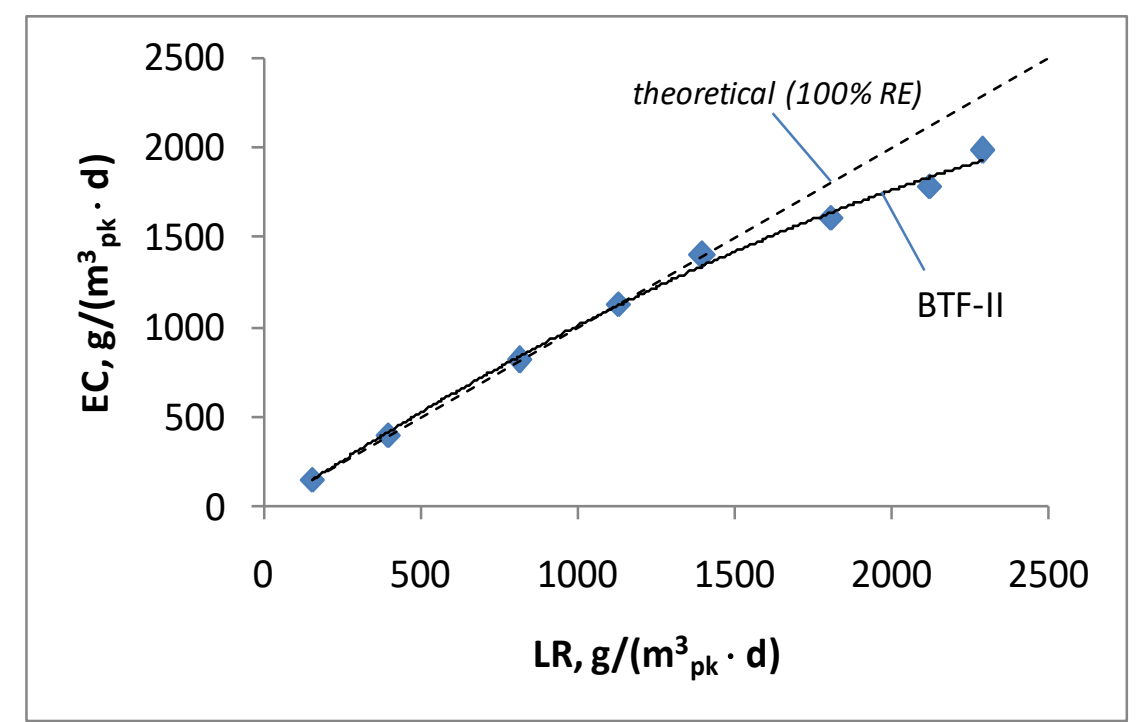

Fig. 3. Variation of the ethanol elimination capacity (EC) as a function of the ethanol loading rate (LR), for BTF-II

Higher LR can be obtained by using higher ethanol concentrations and/or higher gas flowrates. As can be seen in Fig. 4 for BTF-II, the ethanol removal efficiency (RE) decreases with the increase of the gas flowrate above $1 \mathrm{~L} / \mathrm{min}$, which suggest an influence on mass-transfer due the low contact time between the gas and the biological matrix and can explain the limits of the biosystem performance under these conditions.

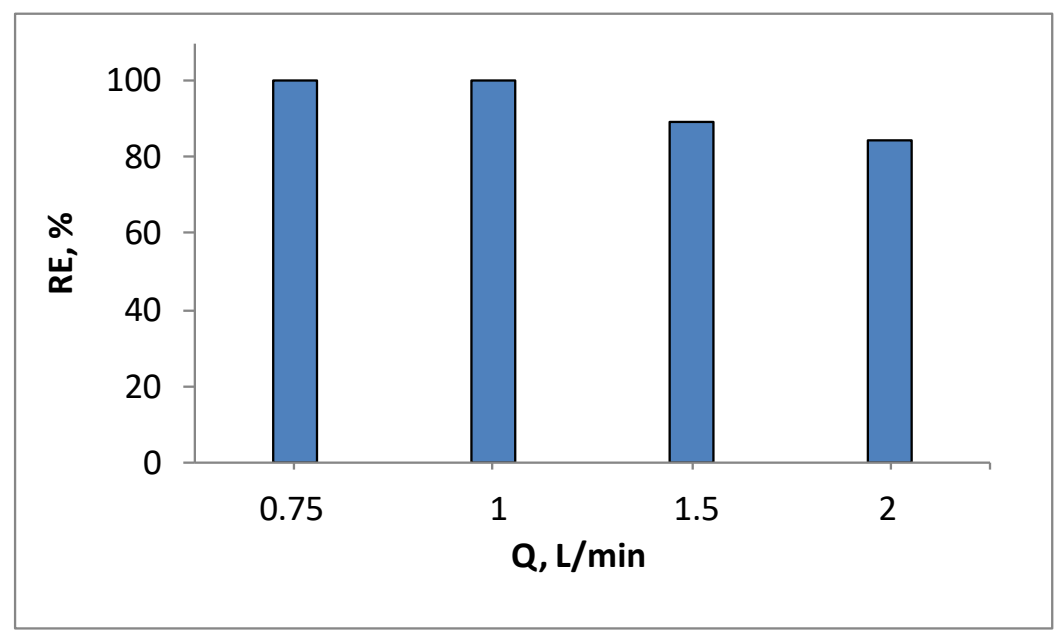

Fig. 4. Variation of the ethanol removal efficiency (RE) as a function of the gas flowrate (Q), for BTF-II, at the initial ethanol concentration of $350 \pm 20 \mathrm{ppm}$ 
The VOCs removal performance obtained in this study (e.g. RE of 84-100\% for LR of up to about $\left.2300 \mathrm{~g} /\left(\mathrm{m}^{3} \cdot \mathrm{d}\right)\right)$ is comparable with that observed in other studies related to the biological removal of ethanol from air by compost-based microorganisms, where for similar ethanol loading rates, RE was above $85 \%[16,17]$. This demonstrates that the addition of the microalgae in such biosystems doesn't affect their VOCs removal performance, but rather co-immobilised microalgae uptakes the carbon dioxide issued from the VOCs biodegradation (and also from inlet air) and potentially contributes to the overall VOCs removal performance.

\section{Future perspectives}

The obtained results are specific for set-up operational conditions and used inoculums. Although the presence of the compost-based microorganisms is beneficial to A. platensis development in the presence of the ethanol [3], A. platensis can develop a mixotrophic behaviour [18-20] when exposed to the organic compounds and this hypothesis needs longer time to be explored towards its potential effect on the isolated heterotrophic microorganisms from commercial compost (e.g. competition for substrate - organic carbon). Overall, the microorganisms' density, along with the microalgae: bacteria ratio control via some specific conditions (e.g. $\mathrm{pH}$, light, nutrients) could be envisaged for establishing a well-balanced symbiosis within the system and reaching the expected process performance. Correlation of these conditions with the immobilisation aspects (e.g. alternative immobilisation techniques, polymer types, ingredients \& recipes, structure designs) could be also envisaged for enhanced mass-transfer and stability of the support material and its microbiota development during long-term operation of such systems.

\section{CONCLUSIONS}

Although the both BTFs (BTF-I and BTF-II) exhibited similar initial performances (EC, RE), the BTF-II was associated with lower $\mathrm{CO}_{2}$ emissions $\left(\mathrm{P}_{\mathrm{CO} 2}\right)$ and higher packing bed durability. Overall, the microalgae contributed to the decrease in the $\mathrm{P}_{\mathrm{CO} 2}$ associated with the BTFs operation and potentially contributed to the overall VOCs removal performance.

The BTF-II-based option over-performed other BTFs in terms of the global warming potential (GWP) reduction. For instance, moving forward using entrapped co-immobilised microorganisms (microalgae and VOC-degraders) could represent an important direction to be considered for further development of sustainable BTFs treating air contaminated with VOCs, their performance being subject to the environmental conditions and the type of the polymeric material involved in the synthesis of the packing beads.

\section{ACKNOWLEDGEMENTS}

This work was supported by a grant of the Ministry of Research, Innovation and Digitization, CNCS/CCCDI - UEFISCDI, project number 301PED/2020, within PNCDI III.

\section{REFERENCES}

[1] SHAREEFDEEN, Z., From Biofiltration to Promising Options in Gaseous Fluxes Biotreatment: Recent Developments, New Trends, Advances, and Opportunities (chapter 6), Elsevier, Amsterdam, 2020, p. 111-127, https://doi.org/10.1016/C2018-0-03712-3.

[2] BARBUSINSKI, K., URBANIEC, K., KASPERCZYK, D., THOMAS, M., From Biofiltration to Promising Options in Gaseous Fluxes Biotreatment: Recent Developments, New Trends, Advances, and Opportunities (chapter 2), Elsevier, Amsterdam, 2020, p. 29-51, https://doi.org/10.1016/C2018-0-03712-3.

[3] SOREANU, G., DiACONU, M., MAIER, S.S., VOLF, I., CRETESCU, I., $7^{\text {th }}$ World Multidisciplinary Earth Sciences Symposium WMESS 2021, 06-10 September 2021, Prague, Czech Republic, IOP Conference Series: Earth and Environmental Science (in press).

[4] MORENO-GARRIDO, I., Bioresour. Technol., 99, 2008, p. 3949.

[5] DZIONEK, A., WOJCIESZYŃSKA, D., GUZIK, U., Electron. J. Biotechnol., 23, 2016, p. 28. 
[6] KUBE, M., SPEDDING, B., GAO, L., FAN, L., RODDICK, F., J. Chem. Technol. Biotechnol., 2020, https://doi.org/10.1002/jctb.6377.

[7] MALLICK, N., Methods in Biotechnology: Immobilization of Enzymes and Cells (chapter 33), Second Edition, Humana Press Inc., Totowa, 2008, p. 373-391, https://doi.org/10.1007/978-159745-053-9_33.

[8] AMENORFENYO, D.K., HUANG, X., ZHANG, Y., ZENG, Q., ZHANG, N., REN J., HUANG, Q., Int. J. Environ. Res. Public Health, 16, 2019, 1910, p. 1, https://doi.org/10.3390/ijerph16111910

[9] AL-JABRI, H., DAS, P., KHAN, S., THAHER, M., QUADIR, M.A., Water, 13, 2021, p. 1, https://doi.org/10.3390/w13010027

[10] GARCIA, D., POSADAS, E., BLANCO, S., ACIEN, G., GARCIA-ENCINA, P., BOLADO, S., MUÑOZ, R., Biores. Technol., 248, 2018, p. 120.

[11] KATAM, K., SHIMIZU, T., SODA, S., BHATTACHARYYA D., Sci. Total Environ., 707, 2020, 135987, p. 1.

[12] LOPEZ-SERNA, R., GARCIA, D., BOLADO, S., JIMENEZ, J.J., LAI, F.Y., GOLOVKO, O., GAGO-FERRERO, P., AHRENS, L., WIBERG, K., MUNOZ, R., Sci. Total Environ., 692, 2019, p. 259.

[13] DE-BASHAN, L.E., BASHAN, Y., Biores. Technol., 101, 2010, p. 1611.

[14] PATNAIK, S., SARKAR, R., MITRA, A., Indian J. Exp. Biol., 39, 2001, p. 824.

[15] SOO, C.L., CHEN, C.A., BOJO O., HII, Y.S., Int. J. Polym. Sci., 2017, article ID 6951212, https://doi.org/10.1155/2017/6951212.

[16] DASTOUS, P.A., NIKIEMA, J., SOREANU, G., BIBEAU, L., HEITZ, M., Water Air Soil Pollut. - Focus, 8, no. 3, 2008, p. 275.

[17] BALASUBRAMANIAN, P., PHILIP, L., MURTY BHALLAMUDI, S., Chem. Eng. J., 209, 2012, p. 102.

[18] PEREIRA, M.I.B., CHAGAS, B.M.E., SASSI, R., MEDEIROS, G.F., AGUIAR, E.M., BORBA, L.H.F., SILVA, E.P.E., NETO, J.C.A., RANGEL, A.H.N., PLoS ONE, 14, no. 10, 2019, e0224294, p. 1, https://doi.org/10.1371/journal.pone.0224294.

[19] VONSHAK, A., CHEUNG, S.M., CHEN, F., J. Phycol., 36, 2000, p. 675.

[20] MATSUDO, M.C., MORAES, F.A., BEZERRA, R.P., ARASHIRO, R.E., SATO, S., CARVALHO, J.C.M., Ann. Microbiol., 65, 2015, p. 1721, https://doi.org/10.1007/s13213-0141011-z.

Citation: Soreanu, G., Diaconu, D., Maier, S.S., Volf, I., Cretescu, I., Moving forward sustainable solutions for VOCs biotrickling filtration through co-immobilised microorganisms, Rom. J. Ecol. Environ. Chem., 2021, 3, no.2, pp. 54-60.

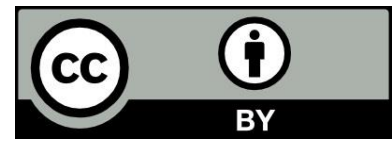

(C) 2021 by the authors. This article is an open access article distributed under the terms and conditions of the Creative Commons Attribution (CC BY) license (http://creativecommons.Org/licenses/by/4.0/). 